İŞLETME ARAŞTIRMALARI DERGİSI
JOURNAL OF BUSINESS RESEARCH-TURK
2020, 12(4), 3747-3758
https://doi.org/10.20491/isarder.2020.1070

\title{
İşgören Seçiminde İnsan Kaynakları Analitiği (İKA) Yaklaşımının Kullanılması (The Use of Human Resources Analytics Approach in Employee Selection)
}

\section{Kemal DEMİ iD a Eyüp ÇALIK iD $b$}

a Yalova Üniversitesi, İktisadi ve İdari Bilimler Fakültesi, İşletme Bölümü, Yalova, Türkiye. kemal.demir@yalova.edu.tr

b Yalova Üniversitesi, Mühendislik Fakültesi, Endüstri Mühendisliği Bölümü, Yalova, Türkiye. ecalik@yalova.edu.tr

\begin{tabular}{|c|c|}
\hline MAKALE BİLGİSİ & ÖZET \\
\hline $\begin{array}{l}\text { Anahtar Kelimeler: } \\
\text { İnsan kaynakları analitiği } \\
\text { İsgören seçimi }\end{array}$ & $\begin{array}{l}\text { Amaç - Bu çalışmanın temel amacı, ulusal literatürdeki boşluğu doldurmak için, çalışanların } \\
\text { seçimine yönelik sinıflandırma tahmininde insan kaynakları analitiği yöntemlerinin nasıl } \\
\text { uygulanabileceğini bir vaka üzerinde göstermektir. }\end{array}$ \\
\hline $\begin{array}{l}\text { Veri analitiği } \\
\text { Modelleme }\end{array}$ & $\begin{array}{l}\text { Yöntem - Sınıflandırma tahmin yöntemlerinden rassal orman, gradyan artırımlı karar ağacı (GBT), } \\
\text { lojistik regresyon, KNN ve naif bayes yöntemleri kullanılmış, yeni aday sınıf etiketleri ise gradyan } \\
\text { artırımlı karar ağacı yöntemi kullanılarak tahmin edilmiştir. }\end{array}$ \\
\hline $\begin{array}{l}\text { Gönderilme Tarihi } 1 \text { Ekim } \\
2020 \\
\text { Revizyon Tarihi } 17 \text { Kasım } 2020\end{array}$ & $\begin{array}{l}\text { Bulgular - Sözü edilen yöntemlerin vaka özelinde yakın sonuçlar verdiği görülmüştür. GBT } \\
\text { yöntemi tercih edilerek işgören seçimi kriterlerinin göreceli ağırlıkları elde edilmiştir. Ar-Ge birimi } \\
\text { için genel yetenek testi en belirleyici kriter olurken başvuru kanalı, sertifika sayısı, cinsiyet ve eğitim } \\
\text { seviyesinin adayın uygunluğunun belirlenmesinde çok ciddi bir ayrım yapmadığı görülmüştür. }\end{array}$ \\
\hline $\begin{array}{l}\text { Makale Kategorisi: } \\
\text { Araştırma Makalesi }\end{array}$ & $\begin{array}{l}\text { Tartışma - İşgören seçiminde elde edilen sonuçların uluslararası literatürdeki benzer çalışmalarla } \\
\text { uyumlu olduğu görülmüştür. Seçilen öznitelikler ile yapılan modellemede, işgören seçim } \\
\text { kriterlerinin farklı ağırlıklarla sınıflandırma başarısına etki ettiği ve bu kriterlerin Ar-Ge biriminin } \\
\text { doğasına uygun olarak konumlandığı şeklinde yorumlanmıştır. Bununla birlikte Türkiye'de faaliyet } \\
\text { gösteren işletmelerin İK veri setleri kullanılarak Türkiye bağlamında işgören seçim sürecinin } \\
\text { görünümüyle ilgili çalışmaların yapılabileceği değerlendirilmiştir. }\end{array}$ \\
\hline
\end{tabular}

\begin{tabular}{|c|c|}
\hline ARTICLE INFO & ABSTRACT \\
\hline $\begin{array}{l}\text { Keywords: } \\
\text { Human resources analytics } \\
\text { Employee selection } \\
\text { Data analytics } \\
\text { Modeling }\end{array}$ & $\begin{array}{l}\text { Purpose - The main purpose of this study is to show how human resources analytics methods can } \\
\text { be applied in classification prediction for the selection of employees on a case to fill the gap in the } \\
\text { national literature. } \\
\text { Design/methodology/approach - Random Forest, GBT, logistic regression, KNN and Naive Bayes } \\
\text { methods were used among the classification prediction methods. The classification labels of } \\
\text { employee candidates were estimated using the gradient incremental decision tree method. }\end{array}$ \\
\hline $\begin{array}{l}\text { Received } 1 \text { October } 2020 \\
\text { Revised } 17 \text { November } 2020 \\
\text { Accepted } 14 \text { December } 2020\end{array}$ & $\begin{array}{l}\text { Findings - It has been observed that the afore mentioned methods gave close results on a case-by- } \\
\text { case basis. The relative weights of the employee selection criteria were obtained by choosing the } \\
\text { GBT method. For the R\&D department appliciants' suitability, while general aptitude test has been } \\
\text { the most significative criteria; reference channel, number of certificates, gender and the education } \\
\text { level have not made a serious distinction. }\end{array}$ \\
\hline $\begin{array}{l}\text { Article Classification: } \\
\text { Research Article }\end{array}$ & $\begin{array}{l}\text { Discussion - It is seen that the results obtained in employee selection are similar to the ones in } \\
\text { international literature. The modelling made with the attributes selected, the criteria of employee } \\
\text { selection affects the classification success in various weight and the criteria are located in accordance } \\
\text { with the nature of the R\&D department. However, it is evaluated that by using the HR datasets of } \\
\text { the companies in Turkey, further studies can be done on the appearance of the employee selection } \\
\text { process in the context of Turkey. }\end{array}$ \\
\hline
\end{tabular}




\section{Giriş}

İşe alma konusu iş seçimi, mesleki seçim, terfi ve yedekleme planlaması, işten ayrılma ve kişi-çevre uyumu dâhil olmak üzere diğer birçok literatürle etkileşim içindedir. Bununla birlikte işe alım, özünde, firmaların strateji uygulamasını ve rekabet avantajı sağlamak için doğru insanı doğru işe doğru zamanda ve yerde bulmak ve yerleştirmektir. Günümüzün ticari, ekonomik ve toplumsal dinamikleri önceki dönemlerden çok farklıdır. Küreselleşme, internet ve mobil teknolojiler, demografik değişimler, ekonomik belirsizlik ve değişimin meydana gelme hızı, tüm işletmecilik uygulamalarında olduğu gibi işe alımda da bir dizi zorluk meydana getirmektedir. İşletmeler stratejilerini hayata geçirmekte kendilerine katkı sağlayacak olan dünyanın farklı bölgelerinde yaşayan ve farklı kariyer amaçları olan adaylara ulaşmak ve onları cezbetmek için çeşitli politikalar geliştirmektedir. Fakat işe alımda doğru karar verebilmek hala en önemli sorundur (Ployhart vd., 2017:292).

Bu soruna dikkat çeken Harvard Business Review'a göre, işletmelerde çalışan devir oranının yüzde 80'i hatalı işe alım kararlarından kaynaklanmaktadır. İnsan Kaynakları Yönetimi Derneği ise yanlış işe alma kararlarının maliyetinin, yıllık maaşın beş katına kadar artabileceğini tahmin etmektedir. Bu nedenle, şirketin yetenek yatırımını bilgece yapmasını sağlamak hem uzun vadeli hem de kısa vadeli başarı için kritik öneme sahiptir (Isson ve Harriott, 2016:82). Bu bağlamda, en uygun adayların işe alımı İK biriminin birincil hedefi ve çözmesi gereken önemli bir problemidir. Bu problemi olabildiğince objektif bir biçimde çözmek için geçmişten bu yana birçok yöntem uygulanagelmiştir.

Yukarıda sözü edilen probleme odaklanarak, literatürde ve uygulamada yüzyılı aşkın bir süreden bu yana, işgören seçimi hakkında oldukça geniş bir birikim oluşmuştur. İşgören seçme işlevinin doğru ve verimli bir biçimde yerine getirilme kaygısının bilimsel çabaya konu olmasının tarihi, Alman psikolog William Wundt'un kendi deneysel psikoloji laboratuvarını kurduğu ve işletmelere yönelik çalışmalar yaptığı 1879 yılına kadar gitmektedir. Wundt, psikolojinin genel kurallarıyla ilgilenirken Cattell 1890 yılında "zihinsel testler" olarak isimlendirdiği yöntemi kullanarak bireysel farklılıklar üzerinde çalışmaktaydı (Vinchur ve Bryan, 2012:10). Cattell'dan günümüze kadar işgören seçiminde gözlem, farklı türdeki testler, mülakat, deneyler, oyunlaştırma, çok kriterli karar verme gibi birçok yöntem kullanılmıştır. Sözü edilen yöntemlerin başlıca ortak amacı nesnel ve doğru bir seçim yapabilmektir. Doğru seçim ile kastedilen ise işgören adayının iş ortamındaki performansını ve davranışlarını önceden tahmin edebilmektir. Nesnel değerlendirme yapmanın ve doğru kararlar almanın başlıca gerekliliklerinden birisi ise bu işlemlerin veriye dayalı olarak gerçekleştirilmesidir. Günümüzde diğer işletmecilik fonksiyonları gibi insan kaynakları da giderek artan bir biçimde veriye dayalı olarak yönetilmektedir. Bu bağlamda, iş analitiğinin bir alt dalı olan İnsan Kaynakları Analitiği (IKKA) diğer işgören seçme yöntemleri ile aynı amaçla kullanılmaya başlanmıştır. İKA günümüzde gerek literatürde gerekse uygulamada kendisine yoğun bir biçimde yer bulmaktadır. Başlıca insan kaynakları fonksiyonlarının hemen hepsinde uygulanan İKA, özellikle işgören seçiminde daha yaygın olarak kullanılmaktadır. Buna ilişkin araştırmalar uluslararası literatürde son yıllarda öne çıkmakta iken ulusal ölçekte Çalık ve Demir (2020) tarafından yazılan kitap dişında bu konuda herhangi bir çalışmaya henüz rastlanılmamaktadır. Bu çalışmada ulusal literatürdeki sözü edilen boşluk dikkate alınarak işgören seçiminde İKA yaklaşımı örnek bir vaka üzerinden ele alınacaktır.

\subsection{Insan Kaynakları Analitiği}

İnsan kaynakları analitiğinin literatürde farklı tanımlamaları bulunmakla beraber bu çalışmada "İK problemlerine çözüm üretmek amacıyla veri analitiği yöntemlerinin kullanılarak, İK ve ilgili verilerin, özellikle geleceğe yönelik tahminler için, analizinin yapılarak iş değeri oluşturulması" şeklinde tanımlanmaktır. İş analitiğinin bir alt dalı olan insan kaynakları analitiği, klasik İK fonksiyonlarının tamamında uygulanabilmektedir. Bununla birlikte, literatür incelendiğinde konunun farklı isimlendirmeler ve modellemeler altında ele alındığı ve sınıflandırıldığ1 görülmektedir. Örneğin Fitz-enz (2010:202) insan sermayesi analitiği bağlamında ölçülmesi gereken altı temel süreci işe alım, öğrenme ve gelişme, performans, yetenek, liderlik olarak sıralamıştır. Handa ve Garima (2014) ise işe alma, eğitim ve gelişim, ücretlendirme, performans değerlendirme, yetenek yönetimi/yedekleme planlama, işten ayrılma olarak yine altı başlıkta ifade etmiştir. Malisetty vd. (2017) daha farklı bir bakış açısıyla İKA modellemelerini çalışan profili oluşturma, çalışan tutumu ve sadakat analizi, insan kaynakları kapasitesinin 


\section{K. Demir - E. Çalık 12/4 (2020) 3747-3758}

tahmini ve işe alma ihtiyaçları, uygun işe alım profili seçimi, çalışan duygu analizi, çalışan dolandırıcılık riski yönetimi başlıklarında sınıflandırmışlardır. Dikkat çeken bir diğer sınıflandırma çalışması Mishra vd. (2016) tarafından gerçekleştirilmiştir. Buna göre, İKA modellemeleri işgücü devir modelleme, yanıt-tepki modelleme, çalışan elde tutma modellemesi, risk modelleme, yetenek tahmini modellemesi olarak sıralanmaktadır. Modellemelere daha klasik bir yaklaşım sergileyen Isson ve Harriott (2016:72) ise, işgücü planlaması, kaynak bulma/kullanma, işe alma, çalışanın işe alıştırılması, kültürel uyumu ve katılımı, çalışanı kaybetme ve elde tutma, performans değerlendirme ve geliştirme ve çalışanların yaşam boyu değeri, çalışanların sağlığı ve güvenliği başlıklarını önermişlerdir. Literatürdeki sözü edilen bu tarz yaklaşımlarının ortak yönlerine bakıldığında, işletmeler açısından kritik önemde olan işe alım/işgören seçme fonksiyonunun hemen hepsinde önemli bir yer tuttuğu görülebilir. İKA bağlamında işgören seçim sürecinin temel amacı veri analitiği yöntemleri yardımıyla işgören adaylarının uygunluğunun tahmin edilerek, nesnel, doğru ve değer üreten kararlar verilmesini sağlamaktır. Bu çalışmada da işgören seçiminde veri analitiği yöntemleri kullanılarak örnek uygulama üzerinden insan kaynakları analitiği uygulaması gerçekleştirilmiştir.

\subsection{Literatürde İşgören Seçimi İ̧̧in Kullanılan Yaklaşımlar}

İşgören seçiminde kullanılan yöntemlerin tarihsel seyrini Vinchur ve Bryan, (2012:11-21) oldukça detaylı bir biçimde incelemiştir. Buna göre; 1900'lü yılların başlarında bireysel farklılıkların ölçülmesinde nicel ölçütlerin ve testlerin kullanılması artmış, Hugo Münsterberg'in öncülüğünde endüstriyel psikoloji, Walter Dill Scott'un öncülügüünde işgören seçme işi önemli gelişme göstermiş ve ilk dünya savaşının da etkisiyle, seçme pratikleri yoğunlaşmıştır. Bu dönemde kullanılan işgören seçme araçlarına örnek bağlamında başvuru formu, mülakat değerlendirme ölçeği, zekâ testleri (hatta grup zekâ testleri) ve dikkat testleri ifade edilebilir. 1930'lu yillara gelindiğinde değerlendirme merkezlerinin erken bir örneğinin oluşturulduğu, ikinci dünya savaşı ve takip eden yıllarda ise seçme işlemlerine dair araştırma ve uygulama merkezlerinin önemli ölçüde arttığı, biyografik verilerin, test türlerinin ve mülakat yönteminin yoğun bir biçimde kullanılmaya devam ettiği söylenebilir. 1960'larda yetersiz görülen ve eleştirilen tekil seçme araçları yerine seçme işlevine daha sofistike yaklaşılarak entegre bir seçim modeli arayışına ilişkin araştırmaların artması dikkate değer bir gelişmedir. Bununla birlikte çok değişkenli istatistiksel tekniklerin işgören seçme süreçlerinde kullanımının artması ancak 1970'lerde başlamıştır. 1990'dan günümüze gelinceye değin, bilgisayarların, internet teknolojilerinin, mobil ve sosyal medya platformlarının işgören seçme işlevinde çok önemli bir yer tuttuğu da ifade edilmelidir.

Tarihsel perspektiften bakıldığında, işgören seçme ve yerleştirme yöntemleri özetle, mülakat, özgeçmiş inceleme ve analiz, simülasyonlar, bireysel psikolojik testler, adayın kendisiyle ilgili oluşturduğu raporlar, tahmine dayalı önyargılar, web tabanlı değerlendirme, veri temelli karar verme olmak üzere geniş bir skalada yer almaktadır.

Diğer yandan işgören seçiminde kullanılan kriterleri ağırlıklandırarak karar vermeyi destekleyen çok kriterli karar verme teknikleri hem uluslararası hem ulusal yayınlarda uzun yıllardır yaygın olarak kullanılmaya devam etmektedir. Son yıllardaki işgören seçimi ile ilgili yapılan güncel uluslararası çalışmalara Salehi (2016) tarafından bulanık AHP ve VIKOR'un entegre edilerek kullanılması, Jasemi ve Ahmadi (2018) tarafından bulanık ELECTRE ve Krishankumar vd. (2020) tarafından sezgisel bulanık VIKOR yönteminin kullanıldığı çalışmalar örnek verilebilir. Ulusal çalışmalara ise, işgören seçiminde TOPSIS yöntemi (Korkmaz, 2018); AHP yöntemi (Akyurt, 2019); MULTIMOORA yöntemi (Kuşakçı vd., 2019) şeklinde sadece tek bir yöntemi kullanan araştırmaların yanı sıra Demirci ve Kılıç (2019) tarafından DEMATEL, ANP ve ELECTRE yöntemlerinin entegre edilmesi ile elde edilen çok kriterli karar verme modelini kullanan güncel çalışmalar örnek olarak verilebilir. Ulusal alanda bulanık ÇKKV yöntemlerini kullanan çalışmalara ise, personel seçiminde bulanık AHP yöntemini kullanan (Güngör, vd. 2009) ile Vatansever ve Oncel, (2014) tarafından akademik personel alımları için bulanık AHP ve bulanık TOPSIS yöntemlerini birlikte ele alan bir çalışma örnek olarak verilebilir. Bu analitik yaklaşımların ötesinde günümüzde giderek artan yoğunlukta, çalışmanın da odak noktası olan, işgören seçiminde veri analitiği yöntemleri kullanılmaktadır. 


\section{3. İsgören Seçiminde Veri Analitiğinin Kullanılması}

İşgören seçiminde veri analitiği yöntemleri kullanılarak yapılan araştırmalara örnek olarak öne çıkan birkaç çalışmadan bahsedilecektir. Chien ve Chen (2008) tarafından yapılan bir çalışmada, işgören seçimi için birliktelik kuralları ve karar ağacı yöntemlerini temel alan bir veri madenciliği modeli geliştirilmiş ve personele ait 8 öznitelik (Yaş, cinsiyet, medeni durum, deneyim, eğitim durumu, pozisyon, mezun olunan okulun seviyesi, işe alım kanalı) kullanılarak tahmin yapılmıştır. Sözü edilen bu 8 karakteristik özellikle iş davranışları arasındaki ilişkiyi ele alan bir konferans bildirisinde ise, inşaat firmasının insan kaynağı planlamasının etkinliğini artırabilmek amacıyla karar ağacı yöntemi kullanan bir model önerilmiştir (Youzheng ve Ming, 2008). Bununla birlikte, Jantan ve arkadaşları farklı yıllardaki çalışmalarında, veri madenciliği algoritmalarından bazılarını (karar ağacı, rassal orman, yapay sinir ağları, vb.) yetenek seçimi için kullanmışlardır (Jantan vd., 2009, 2011a, 2011b). Daha güncel bir çalışmada ise, üniversiteye başvuru yapan akademik personelin seçimi için karar ağacı algoritması kullanılarak bir işe alım modeli oluşturulmuştur (Shehu ve Saeed, 2016). Bir başka güncel çalışmada ise, Shehu ve Besimi (2018), çeşitli veri analitiği teknikleri kullanarak bir tavsiye modeli geliştirmişler ve İsviçre'de haftada beşten fazla açık pozisyon yayınlayan sekiz şirkette ve 50 iş başvurusunda bulunan adayların seçiminde kullanmışlardır. Son olarak, Pessach vd., (2020) tarafından yapılan bir çalışmada, işe alım tahmini için 2000-2010 yılları arasında işe alınan çalışanların istihdam vakaları (yaklaşık 700.000 vaka) temel alınmış ve veri setindeki işe alım öncesi özellikler arasında yaş, cinsiyet, aile ve medeni durum, ikametgah, milliyet ayrıntıları, geçmiş kaydı, eğitim ve notlar, mülakatlar ve test puanları (liderlik puanları ve dil puanları dahil), mesleki tercih anketleri, varsa aile ayrıntıları ve yaşam tarzı verileri ve pozisyonlar hakkındaki bilgiler öznitelik olarak ele alınıp, Variable-Order Bayesian Network (VOBN) yöntemi kullanılarak sınıflandırma tahmini yapılmıştır.

\section{Yöntem}

\subsection{Sinıflandırma Yaklaşımı}

İşgören seçim süreci veri analitiği bakış açısıyla ele alındığında işgören adayının uygunluğu kararı, basitçe 'uygun' veya 'uygun değil' şeklindeki bir sınıflandırma problemidir. Sınıflandırmadaki temel amaç, öznitelik (attributes) olarak tanımlanan belirli özellikleri ve değişkenleri göz önünde bulundurarak yeni bir adayın hangi sınıfa gireceğini tahmin edebilmektir. Dolayısıyla işe alınacak bir adayın şirket için uygun olup olmadığı yani hangi sınıfa gireceğinin tahmin edilmesi, bir sınıflandırma problemidir ve bu şekilde ikili (binary) bir hedef yani çıtı değişkenin olduğu bir model, sınıflandırma tahmini için yeterlidir.

Sinıflandırma, genel olarak bir öğrenme ve test adımından (sınıflandırma modelin doğrulanması) ve bir sınıflandırma adımından (sınıflandırılmamış verinin tahmini için modelin kullanılması) oluşan iki aşamalı bir süreçtir. İlk aşamada eldeki veriler kullanılarak model eğitilir ve daha sonra test verileri ile karşılaştırılarak doğrulama yapılır. Eğer model (bir anlamda kullanılan algoritma) yeterli sınıflandırma başarısı gösteriyorsa ikinci aşamaya geçilerek, sınıflandırılmamış verinin hangi sınıfa gireceği tahmini yapılır (Han vd., 2012:330). Bu aşamalar tipik bir makine öğrenmesi algoritmasının çalışma prensibidir ve Şekil 1'de gösterilmiştir. 


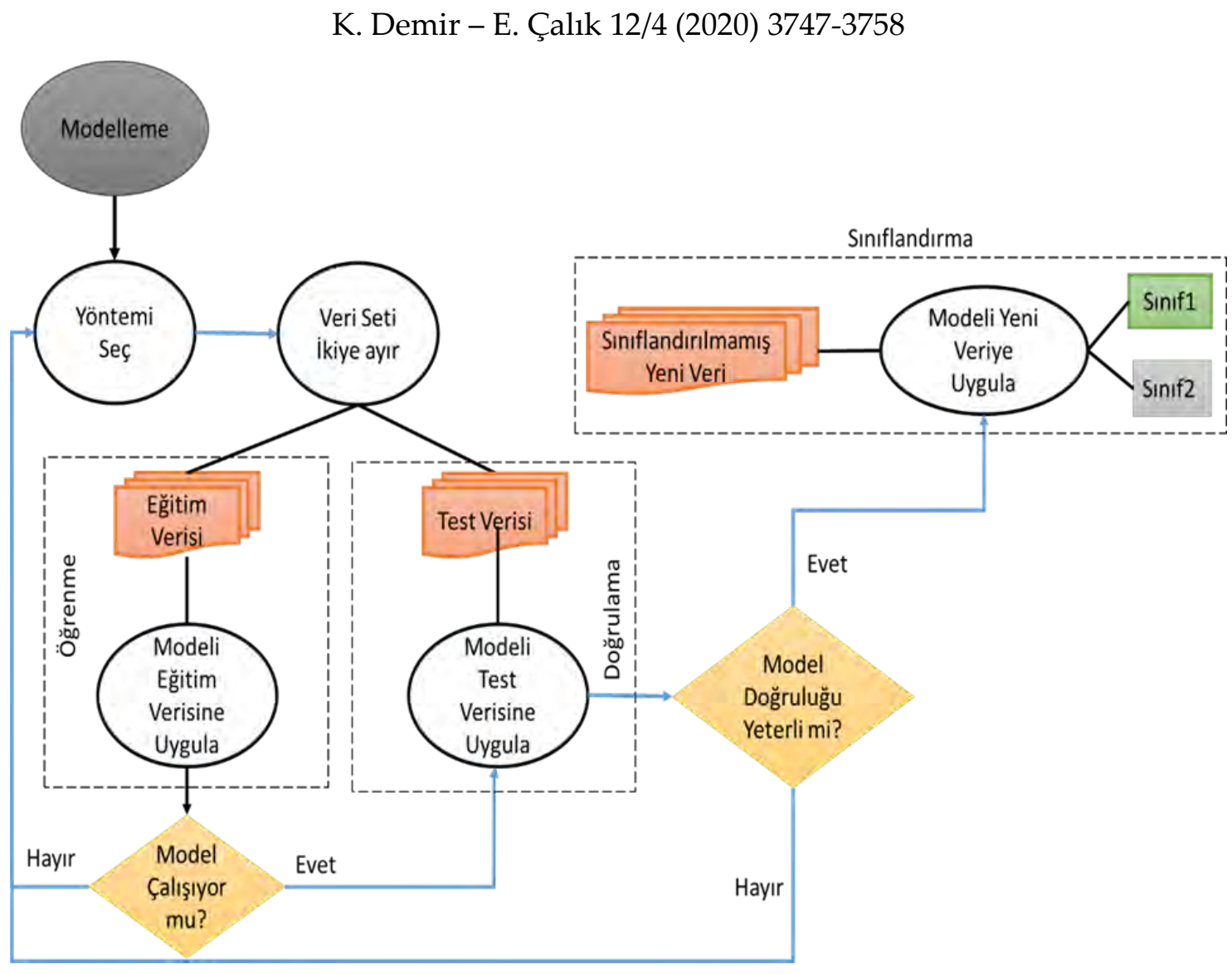

Şekil 1. Sınıflandırma Yaklaşımı

Diğer yandan sınıflandırma için kullanılabilecek alternatif yöntemlerin seçilmesinde ise öncelikli olarak sınıflandırma başarısı yani doğruluğu daha yüksek olan algoritmanın seçilmesi tercih edilir. Doğruluk (Accuracy) ölçütünün yanı sıra özellikle modelin ele alınış biçimine göre Kesinlik Ölçütü (Precision), Duyarlılı Ölçütü (RecallSensitivity), Özgünlük Ölçütü (Specificity), F Ölçütü (F Measure) gibi ölçütler ve AUC-ROC Ĕ̆rileri de kullanılmaktadır. Bu ölçütlerin dışında Hız, Dayanıklılık (Robustness), Ölçeklenebilirlik (Scalability), Yorumlanabilirlik (Interpretability) gibi başka kriterler göz önünde bulundurularak hangi algoritmanın kullanılabileceğine de karar verilebilir (Han vd., 2012:369).

Veri analitiği sürecinde sınıflandırma amacıyla kullanılan yöntemlerin uygulanmasından önce basit bir modelleme yapmak, sürecin verimliliği açısından oldukça önemlidir. Modelleme aşamaları, araştırma hedefinin, analizde kullanılacak değişkenlerin (hedef değişken ve özniteliklerin) ve değişkenlerin nasıl ölçüleceğinin belirlenmesi olarak düşünülebilir. Bu bağlamda işgören seçimindeki en önemli hedefin uygun adayın işe alınması olmasından ötürü, yeni işe alınacak adayın uygun aday olup olmadığını sınıflandırarak tahmin edecek bir modelin kurulması araştırmanın temel hedefidir. Bu hedef bağlamında sınıflandırmada adayın pozisyon için uygunluğu söz konusudur. O halde, 'adayın uygunluğu' olan hedef değişken, 'uygun' ve 'uygun değil' şeklinde 2 kategorili olarak ölçülebilir. Veriler ise örneğin daha önceki işe alımlarda mülakata çağrılanlar veya işe alınanlar 'uygun' olarak, elenenler veya kısa zamanda işten ayrılanlar ise 'uygun değil' olarak İK veri tabanlarından elde edilebilir. Bu hedef değişken karar vericinin isteğine göre, üç kategorili bir gösterge çizelgesi ile de ('kesinlikle uygun'- 'uygun'- 'uygun değil' gibi) değerlendirilebilir. Ancak bu şekilde veriye ulaşmak daha zor olacak ve veri sayısının az olduğu durumlarda model sınıflandırma başarısı daha fazla etkilenecektir. Yine benzer şekilde hedef değişkenin kategorileri [uygun, 'işe alınmış ve uygun olduğu görülerek o pozisyonda istihdam edilmiş çalışan' olarak belirlenirken uygun olmayan, 'işe alınmış ama uygun olmadığı görülmüş çalışan (işten çıkarılmış, farklı bir pozisyona yönlendirilmiş veya belli bir süre içinde istifa edenler vb.)] şeklinde yapılabilir. Örnek olarak Pessach vd., (2020) İK departmanı kayıtlarına dayalı olarak, işe alım durumunu, başarılı işe alımlar ve başarısız işe alımlar şeklinde iki gruba ayırıp, bu şekilde bir hedef değişken belirlemiştir. 


\section{K. Demir - E. Çalık 12/4 (2020) 3747-3758}

Diğer yandan modelde kullanılacak özniteliklerin belirlenmesinde veri tabanlarında var olan işgören seçiminde kullanılabilecek tüm değişkenler ele alınabilir ve karar verici tarafından seçilerek de kullanılabilir. Literatürde işgören seçimi modellemesinde kullanılabilecek bazı özniteliklere, demografik özellikler, eğitim ve yetenek geçmişi, deneyim (Malisetty vd., 2017); işe alım maliyeti, teklif edilen maaş, işe alım süresi (Fitz-enz ve Mattox, 2014:90); toplam yapılan görüşme sayısı, sosyal medya kullanımı (Isson ve Harriott, 2016:177); referans, eğitim, mülakat süreci (Handa ve Garima, 2014) şeklinde yer verilmiştir.

Yukarıda açıklandığı gibi, adayların uygun olup olmadığı şeklinde sınıflandırma tahmini yapılmak istenen işgören seçimi problemlerinde veri analitiği yöntemleri kullanılarak işgören adaylarının firma için uygun aday olup olmadığ olabildiği işgören seçimi modellerinde kullanılabilecek veri analitiği yöntemlerinden kısaca bahsedilecektir.

\section{2. İşgören Seçimi Modelinde Kullanılabilecek Veri Analitiği Yöntemleri}

Sınıflandırma tahmini için kullanılabilecek veri analitiği yöntemlerinden Lojistik Regresyon, Karar Ağaçları, Naif Bayes, K-En Yakın Komşu(K-NN) algoritmalarından, detayları veri madenciliği ile ilgili temel kaynaklara havale edilerek, kısaca bahsedilecektir. Bunların dışında kullanılabilecek veri analitiği yöntemleri (Diskriminant Analizi, Yapay Sinir Ağları, Destek Vektör Makineleri, vb.) olsa da işgören seçiminde kullanılacak kriterlerin doğasına daha uygun sonuçlar verecekleri düşünüldügüunden ve varsayımlarının esnekliğinden dolayı en yaygın olarak kullanılan aşağıdaki yöntemler seçilmiştir.

Lojistik Regresyon, regresyon ailesinin bir üyesi olup, bağımlı değişkenin kesikli (genelde ikili) ve bağımsız değişkenlerin kategorik veya sürekli olduğu durumlarda, bağımlı değişkeni tahmin etmek için kullanılan bir yöntemdir. Lojistik regresyonun çoklu regresyondan temel farkı, bağımlı değişkenin kategorik olmasıdır (Hair vd., 2014:314-316). Eğer bağımlı değişkendeki kategori sayısı ikiden fazla olursa o zaman çok kategorili (multinominal) lojistik regresyon ismini alır. Aynı zamanda lojistik regresyon çoklu regresyonun çoklu normal dağılım vb. katı varsayımlarını istemez. Benzer şekilde değişkenler arası doğrusal bir ilişki olmaması da lojistik regresyonun kullanımını etkilemez (Hair vd., 2014:320). Dolayısıyla, lojistik regresyon, veri analitiği uygulamalarında özellikle hedef değişken sınıfının ikili olduğu sınıflandırma tahminlerinde (var-yok, kabul-ret, uygun-uygun değil vb.) en çok kullanılan yöntemlerin başında gelmektedir. İşgören seçiminde de adayların uygun olup olmadığı şeklindeki ikili sınıf etiketini tahmin etmek için kullanılabilir.

Karar Ağaçları (Decision Trees), yaygın olarak kullanılan ve ağaç temelli birçok algoritmayı içinde barındıran sınıflandırma yöntemleri topluluğunun genel adıdır. Model bir ağaç şeklinde gösterildiği için karar ağacı olarak adlandırılır. Karar ağacı, her bir düğümün bir öznitelik üzerinde bir testi ifade ettiği, her dalın testin bir sonucunu temsil ettiği ve her bir yaprak dügümünün bir sınıf etiketi tuttuğu akış şemasına benzer bir ağaç yapısıdır (Han vd., 2012, s. 330). Karar ağaçlarında önce karar ağacı sonra karar kuralları oluşturularak veri tabanındaki her bir kayıt bu ağaca uygulanır ve çıkan sonuçlara göre kayıtlar sınıflandırılır (Silahtaroğlu, 2013:68). Karar ağaçlarındaki en önemli problemlerden birisi hangi kökten itibaren bölümlenmenin veya hangi düğümden dallanmanın başlayacağı yani hangi kritere göre yapılacağıdır (Özkan, 2016, p. 42). Uygun düğümden başlanmazsa ağacın içerisindeki düğümlerin ve yaprakların sayısı çok fazla olacak ve yorumlama konusunda esneklik sağlamayacaktır. Bu amaçla karar ağacı oluşturmak için ID3, Gini, CHAID vb. birçok algoritma geliştirilmiştir. Bu algoritmalar birbirlerinden, kök, düğüm ve dallanma kriterlerinin seçilmesinde izledikleri yollar bakımından farklılık göstermektedir (Silahtaroğlu, 2013: 74). Tekil karar ağacını içeren bu algoritmaların yanı sıra pek çok karar ağacını bir arada ele alan Rastgele Orman (Random Forest) ve Gradyan Artırımlı Karar Ağaçları (Gradient Boosted Trees-GBT) yöntemleri uygulamalarda öne çıkmaktadır. Bu yöntemler, tek karar ağacı modeline kıyasla daha fazla tahmin doğruluğu ve model yorumlanabilirliği sağlamaktadır. Gradiyant artırımlı modeller, veri analitiğinde kesin ve işlevsel bir yol sağlamak için doğruluk ve yorumlanabilirlik sorunlarını azaltmaya çalışan ağaç pekiştirmenin genelleştirmesi olarak ifade edilmektedir (Hastie, 2009; s.352). Dolayısıyla karar ağaçları algoritmaları gerek sayısal gerekse kategorik değişkenlerin olduğu işgören seçimi problemlerinde kullanılabilir. 


\section{K. Demir - E. Çalık 12/4 (2020) 3747-3758}

Naif (Naive) Bayes, Bayes Teoremini temel alan ve yaygın olarak kullanılan bir sınıflandırma yöntemidir. Naif Bayes sınıflandırıcısı ise sınıflandırma problemlerinde en çok kullanılan türüdür. Bu yöntemde, her bir sınıf için koşullu olasılıklar hesaplanır ve sınıflandırılmamış yeni eleman, sınıf olasılığı en yüksek olan sınıfa atanır. Bu yöntem değişkenlerin birbirinden tamamen bağımsız olduğu varsayımı üzerine kuruludur (Han vd., 2012:352). İşören seçimi problemlerinde özellikle kategorik değişkenlerin fazla olduğu sınıflandırma modellerinde kullanılabilir.

K-En Yakın Komşu (K-Nearest Neighbor/K-NN) yöntemi, uzaklığa dayalı bir sınıflandırma yöntemi olup, mesafeye dayalı sınıflandırma metotları içinde uygulamada kendisine önemli derecede yer bulmaktadır. Bu metot, sınıfları belli olan örnek kümedeki gözlemlerin her birinin, yeni bir gözlem değerine olan uzaklıklarının hesaplanarak, en küçük uzaklığa sahip k sayıda gözlemin seçilmesi esasına dayanmaktadır. Bu şekilde yeni bir gözlemin hangi sınıfa ait olduğu belirlenerek sınıflandırma yapılmış olur (Özkan, 2016:141). Öte yandan eldeki verilerin birbirlerine olan uzaklığı kullanılarak sınıflandırma yapıldığı için değişkenlerin sürekli olması gerekse de kategorik değişkenlerin olduğu durumlarda mesafe hesaplaması için bazı yöntemler önerilmektedir (Han vd., 2012:424). Ancak kategorik değişkenlerin çok olduğu işgören seçimi modellerinde, bu yöntemin istenilen doğrulukta sonuçlar veremeyebileceği de göz önünde bulundurulmalıdır.

\section{3. İsgören Seçimi Örnek Uygulama}

İşören seçimi için kaggle.com adresinden elde dilen bir veri setinden (HR Analytics classification, 2020) faydalanılmıştır. Bu veri seti global bir firmaya ait olup, bilgiler anonim olarak araştırmacıların kullanımına sunulmuştur. Eğitim için oluşturulan 54.808 satırlık veri içerisinden yapılacak yorumlamaların daha nitelikli olması ve veri setindeki özniteliklerin daha ayırıcı sonuçlar verebileceği öngörüsüyle Ar-Ge birimi seçilmiştir. Belirlenen değişkenler (öznitelikler) kullanılarak Ar-Ge birimi için ihtiyaç duyulan işgörenlerin uygunluğunu tahmin edebilmek amacıyla bu değişkenlerin uyarlanması ile vaka Ar-Ge bağlamında yeniden kurgulanmıştır. Dolayısıyla sektörden bağımsız olarak bir şirketin Ar-Ge birimi için işe başvuran adayların uygun olup olmadıkları şeklinde sınıflandırma tahmini yapma hedefiyle örnek uygulama gerçekleştirilmiştir.

\subsection{Veri Önişleme ve Modelin Oluşturulması}

Veri kaynağından alınan işlenmemiş verinin, veri analitiği algoritmalarının uygulanmasından önceki hazırlanma süreci, Veri Önişleme (Preprocessing) olarak nitelendirilmekte ve eldeki verinin temizlenmesi, bütünleştirilmesi, gerekiyorsa daha küçük boyutlara indirgenmesi ve dönüştürülmesi aşamalarını içermektedir (Han vd., 2012:8). Kısaca verinin analiz öncesi hazırlanması gerekmektedir. Bu doğrultuda öncelikle değişkenlerin isimleri ve değerleri Türkçeleştirilmiştir. Sonraki aşamada bölge değişkeni, bölge sayısının çok olmasının yorumlamada karışıklığa sebep olmaması için, veri setinden çıkarılmıştır. İkili olarak 0-1 şeklinde kodlanan değişkenler vakanın anlaşılabilirliğini ve yorumlama kolaylığını artırmak amacıyla isimsel (nominal) değişkene çevrilmiştir. Ar-Ge birimi için toplam veri sayısı 999 olan veri setinde, 28'inin eğitim durumunun; 78'inin ise genel yetenek testi sonuçlarının olmadığı görülmüştür. Bu kayıp değerlerin yerine başka değer eklemenin yanlı sonuçlar üretebileceği öngörülerek bu değerler veri setinden çıkarılmış ve nihai analize girecek veri sayısı 893 olmuştur.

Modelin oluşturulması aşamasında, orijinal veri setindeki KPI performansının \%80'ininin karşılanıp karşılanmadığı şeklinde olan değişken, modelde hedef değişken olarak belirlenmiştir. KPI performansının \%80'inden fazlasını karşılayanlar 'uygun' olarak, bu oranın altında olanlar 'uygun değil' olarak ikili (Uygun/Uygun değil) şekilde nitelendirilmiştir. Modeldeki öznitelikler ise, gerek veri setinde bulunan değişkenler ve gerekse örnek bir vaka olduğu için yorumlamada kolaylık olması açısından Tablo 1'deki gibi belirlenmiş, nasıl ölçüldükleri ve verilerin dağılımıyla ilgili temel açıklayıcı istatistiklere de yer verilmiştir. 
K. Demir - E. Çalık 12/4 (2020) 3747-3758

Tablo 1. Öznitelikler ve Ölçümleri

\begin{tabular}{|c|c|c|c|c|}
\hline \multicolumn{2}{|c|}{ Öznitelik } & Ölçeği & Nasıl Ölçüldüğü & Verilerin Dağılımı \\
\hline 1 & Eğitim seviyesi & Ordinal & Lisans/Y.lisans & Lisans: 495; Lisansüstü: 398 \\
\hline 2 & Cinsiyet & Binominal & Kadın /Erkek & Kadın: 51; Erkek: 842 \\
\hline 3 & Başvuru kanalı & $\begin{array}{l}\text { Polinomin } \\
\text { al }\end{array}$ & İlan/Referans/Diğer & İlan: 378; Referans: 17; Diğer: 498 \\
\hline 4 & Sertifika Sayısı & Sürekli & Alınan Sertifika sayısı & ${ }^{*}$ Min: 1, Maks: 5, Ort: 1.4, ss: 0.69 \\
\hline 5 & Yaş & Sürekli & Kişinin yaşı & Min: 25, maks: 50, ort: 33.35, ss: 4.47 \\
\hline 6 & $\begin{array}{l}\text { Genel Yetenek } \\
\text { Testi }\end{array}$ & Sürekli & 1-5 Skalası & Min: 1, Maks: 5, ort: 3.57, ss: 1.19 \\
\hline 7 & Deneyim & Sürekli & $\begin{array}{l}\text { Mesleğindeki deneyim } \\
\text { y1lı }\end{array}$ & Min:1, Maks: 20, Ort: 4.94, ss: 2.64 \\
\hline 8 & Başarı & Binominal & Uygun-Uygun Değil & Uygun: 383; Uygun Değil: 510 \\
\hline 9 & Ödül & Binominal & Mesleki Ödül (Var/Yok) & Var: 19; Yok: 874 \\
\hline 10 & Yabancı Dil & Sürekli & $\begin{array}{l}\text { Dil Sınav Puanı (100 } \\
\text { puan) }\end{array}$ & Min: 73, Maks: 98, Ort: 84.6, ss: 2.9 \\
\hline 11 & Patent & Binominal & $\begin{array}{l}\text { Patent Sahipliği } \\
\text { (Var/Yok) }\end{array}$ & Var: 58; Yok: 835 \\
\hline
\end{tabular}

*Min: Minimum, Maks: Maksimum, Ort: Ortalama, ss: standart sapma

\section{Bulgular}

Modelde kullanılacak bu özniteliklerin hem kategorik hem de sürekli değişkenler olmasından dolayı önceki bölümde bahsedilen veri analitiği yöntemlerin hepsi kullanılabilir. Model Rapid Miner 9.7 akademik sürümü kullanılarak bu yöntemlerle çalıştırılmış, elde edilen sonuçlar Tablo 2 ve Şekil 2'de gösterilmiştir. Doğrulama amacıyla 10 katmanlı K-Katlamalı Çapraz Doğrulama yaklaşımı kullanılmış ve algoritmaların çalıştırılmasıyla elde edilen sınıflandırma doğruluğu, kesinlik, duyarlılık ve AUC değerleri Tablo 3'te verilmiştir.

Tablo 2. Sinıflandırma Sonuçları

\begin{tabular}{|l|l|l|l|l|l|}
\hline & Rassal Orman & GBT & Naif Bayes & K-NN & Lojistik Regresyon \\
\hline Doğruluk (Accuracy) & $\% 72,5$ & $\% 71,8$ & $\% 69,3$ & $\% 61,2$ & $\% 71,1$ \\
\hline Kesinlik Ölçütü (Precision) & $\% 73,6$ & $\% 70,5$ & $\% 65,3$ & $\% 56,3$ & $\% 68,9$ \\
\hline Duyarlılık Ölçütü (Recall- & $\% 56,2$ & $\% 61,4$ & $\% 61,7$ & $\% 46,3$ & $\% 60,6$ \\
\hline AUC & 0,74 & 0,74 & 0,73 & 0,63 & 0,74 \\
\hline
\end{tabular}

Tablo 2' de görüldüğü üzere, sınıflandırma doğruluğu açısından, K-NN hariç diğer dört yöntem (Rassal Orman, GBT, Naif Bayes, Lojistik Regresyon) yaklaşık \%71 sınıflandırma başarısı ile birbirlerine yakın sonuçlar vermiştir. Rassal Orman yöntemi kesinlik ölçütünde diğerlerine göre daha yüksek iken, duyarlılık ölçütünde diğer 3 yönteme göre daha düşük bir sonuç vermiştir. AUC sonuçlarına bakıldığında ise yine bu dört yöntemin \%73-\%74 şeklinde yakın sonuçlar verdiği ortaya çıkmıştır. Bu sonuçlara göre K-NN hariç diğer dört yöntemin de sınıflandırılmamış verilerin tahmini için kullanılabileceği görülmektedir. Diğer yandan Şekil 2'deki AUC eğrilerine bakıldığında ise, beklenildiği gibi değerlerin birbirine yakın seyretmekle beraber GBT yönteminin bir adım önde olduğu görülecektir. Bundan sonraki aşamada tek bir yöntemle devam etmek anlamlı olduğu için GBT yöntemi ile devam edilmiştir. 


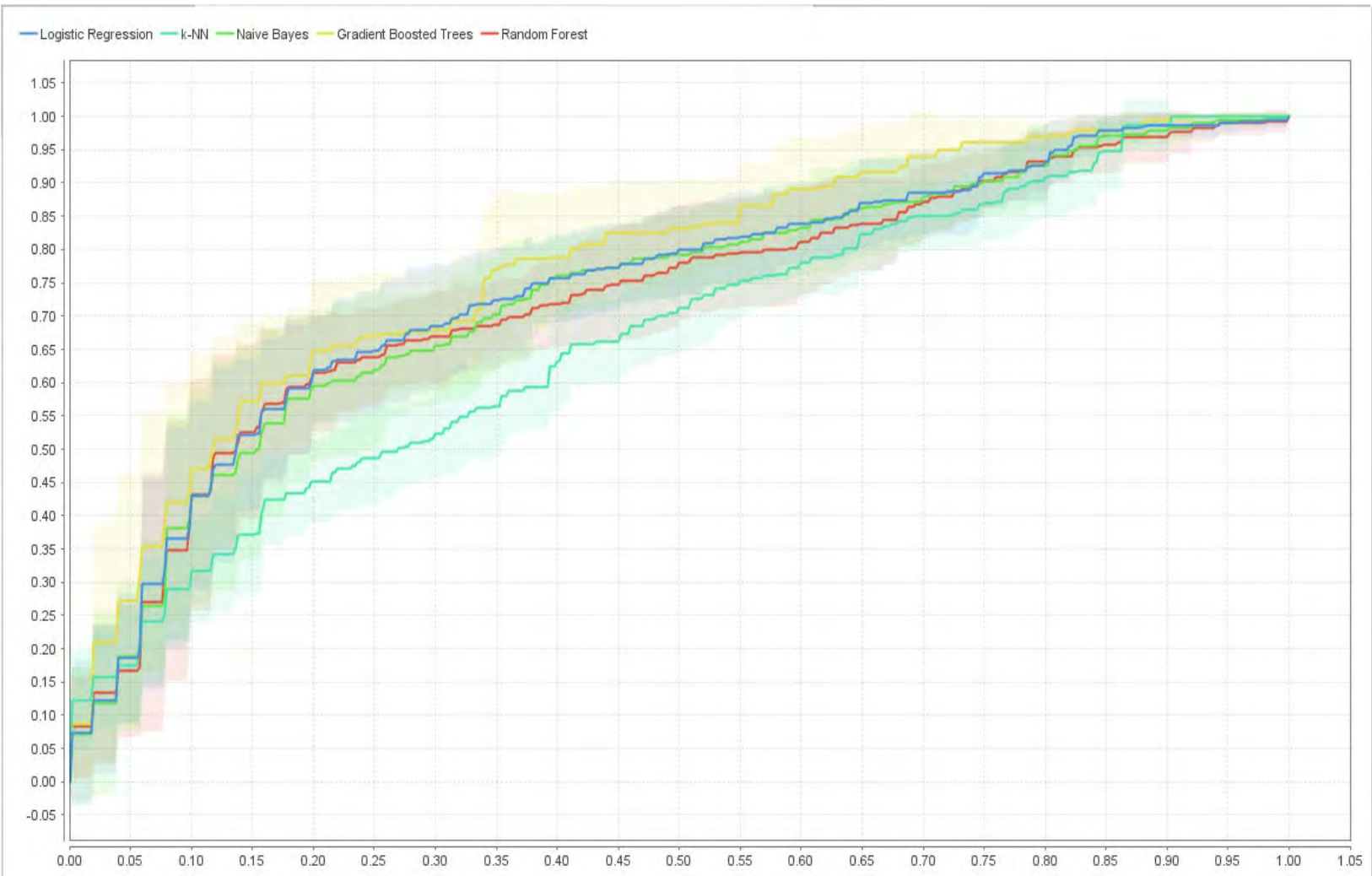

Şekil 2. AUC Eğrisi

\section{1. Özniteliklerin Göreceli A ğırlıkları}

GBT yöntemi ile devam edilerek özniteliklerin sınıflandırmadaki göreceli ağırlıkları da bulunmuştur. Tablo 3'te, sınıflandırma tahmininde en önemli özniteliğin diğerlerine kıyasla büyük bir farkla genel yetenek testi olduğu, görülmektedir. Diğer özniteliklere bakıldığında, patent, ödül, yabancı dil, yaş ve deneyim şeklinde sıralanmıştır. Diğer yandan başvuru kanalı, sertifika sayısı, cinsiyet ve eğitim seviyesinin adayın uygunluğunun belirlenmesinde en az etkili olan öznitelikler olduğu görülmektedir.

Tablo 3. Özniteliklerin Göreceli Ağırlıkları

\begin{tabular}{|c|c|}
\hline Öznitelik & Ă̆ırlık \\
\hline Genel Yetenek Testi & $\% 74,00$ \\
\hline Patent & $\% 8,36$ \\
\hline Ödül & $\% 6,74$ \\
\hline Yabancı Dil & $\% 4,46$ \\
\hline Yaş & $\% 2,99$ \\
\hline Deneyim & $\% 1,75$ \\
\hline Eğitim Seviyesi & $\% 0,94$ \\
\hline Cinsiyet & $\% 0,51$ \\
\hline Sertifika Sayısı & $\% 0,16$ \\
\hline Başvuru Kanalı & $\% 0,10$ \\
\hline Toplam Ağırlık & $\% 100,00$ \\
\hline
\end{tabular}




\subsection{Yeni Adaylarm Sinuflandırılması}

Bu kısma kadar gerçekleştirilen adımlar aslında Şekil 1'de yer alan modelin doğru çalışıp çalışmadığını ve model doğruluğunun yeterliliğini ortaya koyan eğitim, test ve doğrulama aşamalarıdır. Bu kısımda ise, yine Şekil 1'de yer alan, sınıflandırılmamış verinin sınıf etiketi tahmininin yapılması yani yeni bir adayın uygun olup olmadığının tahmini gerçekleştirilecektir. Bu amaçla kullanılan veri setinden bağımsız olarak, hedef değişkeni (uygunluk) belli olmayan yeni 10 adayın öznitelik değerleri rassal olarak oluşturulmuş ve yazılıma girdi olarak verilmiştir. Önceki adımlarda eğitilmiş ve model doğruluğu yeterli olan GBT yöntemi kullanılarak sınıflandırma gerçekleştirilmiş yani adayın uygun olup olmadığı tahmin edilmiştir. Tablo 4'te görüleceği üzere bu model 6 adayı uygun, 4 adayı ise uygun değil olarak tahmin etmiştir.

Tablo 4. Yeni Adayların Tahmin Sonuçları

\begin{tabular}{|l|l|l|l|l|c|l|l|l|l|l|l|}
\hline No & Eğitim & Cinsiyet & Kanal & $\begin{array}{l}\text { Sertifika } \\
\text { Sayısı }\end{array}$ & GY Testi & Yaş & Deneyim & Ödül & $\begin{array}{l}\text { Dil } \\
\text { Puanı }\end{array}$ & Patent & Uygunluk \\
\hline 1 & Lisansüstü & Kadın & İlan & 1 & 3 & 37 & 7 & Yok & 74 & Yok & Uygun Değil \\
\hline 2 & Lisans & Erkek & Referans & 3 & 5 & 40 & 5 & Yok & 84 & Var & Uygun \\
\hline 3 & Lisansüstü & Erkek & Diğer & 1 & 5 & 27 & 1 & Yok & 87 & Yok & Uygun \\
\hline 4 & Lisans & Erkek & İlan & 1 & 4 & 36 & 8 & Yok & 82 & Yok & Uygun Değil \\
\hline 5 & Lisans & Kadın & İlan & 2 & 5 & 47 & 10 & Yok & 78 & Yok & Uygun \\
\hline 6 & Lisansüstü & Kadın & Diğer & 1 & 2 & 37 & 5 & Yok & 90 & Yok & Uygun Değil \\
\hline 7 & Lisans & Erkek & İlan & 2 & 3 & 30 & 4 & Var & 84 & Yok & Uygun \\
\hline 8 & Lisans & Erkek & İlan & 1 & 3 & 27 & 2 & Yok & 76 & Yok & Uygun Değil \\
\hline 9 & Lisansüstü & Erkek & Diğer & 1 & 3 & 30 & 6 & Yok & 72 & Var & Uygun \\
\hline 10 & Lisans & Kadın & İlan & 2 & 5 & 38 & 9 & Yok & 83 & Yok & Uygun \\
\hline
\end{tabular}

\section{Sonuç ve Tartışma}

Bu çalışmada, işgören seçiminde insan kaynakları analitiği yaklaşımının nasıl kullanılacağı örnek uygulama yardımıyla gösterilmesi hedeflenmiştir. Bu amaçla, kaggle.com aracılığıyla elde edilen bir veri seti kullanılarak, K-NN, Rassal Orman, GBT, Naif Bayes ve Lojistik Regresyon yöntemleri yardımıyla, Ar-Ge birimi için uyarlanan bir vaka özelinde sınıflandırma tahmini gerçekleştirilmiştir. K-NN hariç diğer dört yöntemin sınıflandırma başarılarının yaklaşık \%70 olarak birbirine yakın olduğu görülmektedir. K-NN'in göreceli olarak daha düşük bir sonuç vermesinin nedeni modeldeki özniteliklerin birçoğunun kategorik olmasından kaynaklandığı söylenebilir. Bu doğrultuda bu yöntemlerden GBT seçilerek hangi işgören seçim kriterlerinin aday işgören tahmininde daha önemli olduğu bilgisine de ulaşılmıştır. Bu vaka özelinde Ar-Ge adayları için yapılan genel yetenek testinin sınıf tahmininde yüksek ağırlıkla en önemli kriter olduğu görülmüştür. Dolayısıyla Ar-Ge çalışanı işe alımında bu testin ön plana çıktığı ve işe alım yöneticilerinin karar vermesinde etkili olduğu söylenebilir. Ar-Ge çalışanlarının sahip olması gereken profil göz önüne alındığında genel yetenek testinin ön plana çıkması anlamlı görülebilir. Her ne kadar genel yetenek testi kadar yüksek olmasa da göreceli olarak adayın patentinin olması, Ar-Ge faaliyetleri kapsamında alınmış ödül sahibi olması, yaşı ve deneyim süresi de sınıflandırmada etkili olan diğer kriterlerdir. Dolayısıyla bu dört kriterin de adayın araştırma, yeni fikir üretme, geliştirme, tecrübe vb. Ar-Ge yetenekleri için oldukça anlamlı kriterler olduğu ifade edilebilir. Modelin bu kriterleri öncelemesi, model sonuçlarıyla gerçek hayat gereksinimleri arasındaki tutarlılığa işaret ettiği şeklinde yorumlanabilir.

Diğer yandan eğitim seviyesi, cinsiyet, sertifika sayısı ve başvuru kanalının oldukça az etkiye sahip olması şirketin işe alım politikası hakkında yorum imkânı sunmaktadır. Eğitim seviyesi olarak Ar-Ge çalışanlarının lisans ya da 


\section{K. Demir - E. Çalık 12/4 (2020) 3747-3758}

lisansüstü mezunu olmasının anlamlı bir etkisi bulunmamaktadır. Bu firmanın faaliyet gösterdiği sektörde araştırma geliştirme faaliyetleri bünyesinde istihdam edilen çalışanların en az lisans seviyesinde olması önem arz ederken, lisansüstü mezunu olmanın işe alımda ciddi bir ayrıma sebep olmadığı şeklinde yorumlanabilir. Benzer şekilde çalışanların kadın veya erkek olmasının işe uygunluk bağlamında herhangi bir ayırıcı etkisinin olmaması Ar-Ge çalışmalarının doğası gereği oldukça tutarlı bir sonuçtur. Sertifika sayısının etkisinin az olması, şirket için de her ne kadar işe alımda sertifika sayısı bir kriter olarak ele alınsa da karar verici için asıl belirleyici bir kriter olmadığı şeklinde yorumlanabilir. Son olarak başvuru kanalının en az etkiye sahip olan kriter olması, Ar-Ge çalışanlarının farklı işe alım kanallarından işe başvuru yapmasının işe alım kararlarında ciddi bir ayrım yapmadığının bir göstergesi olarak ifade edilebilir. Buna ek olarak veri setinde referanslı alınan aday sayısının oldukça az olmasının da bu sonucu etkileyebileceği dikkate alınmalıdır.

Diğer yandan çalışmanın temel hedefi olan yeni adayların sınıflandırılması örnek 10 veri üzerinden gerçekleştirilmiştir. Literatürde örnek olarak verilen çalışmalarda olduğu gibi, bu çalışmada da işgören seçiminde veri analitiği yöntemleri kullanılarak adayların uygun olup olmadığının tahmin edilmesiyle İK karar vericileri için bir iş değeri oluşturulabileceği görülmüştür.

İleriki çalışmalarda, Türkiye'de faaliyet gösteren işletmelerin işgören seçimine ilişkin veri setleri üzerinden insan kaynakları analitiği çalışmaları yapılarak, Türkiye bağlamında işgören seçim süreçlerinin görünümü ortaya konabilir. Bu sayede ülkemizdeki işletmelerin örgütsel yapı ve kültürlerine uyumlu işe alım politikaları oluşturmalarına da katkı sağlanabilir. Ayrıca, literatürde genişçe yer bulan ÇKKV teknikleri ve bu çalışmada kullanılarak gösterilen veri analitiği yöntemlerinin işgörenlerin seçiminde birlikte kullanılabileceğini gösteren çalışmalar yapılabilir.

\section{Kaynakça}

Akyurt, Ö. Ü. H. (2019). Analitik hiyerarşi seçim yöntemi ile otel personeli seçimi kriterlerinin değerlendirilmesi: Giresun ili örneği, IBAD Sosyal Bilimler Dergisi, 64-78.

Chien, C. F., \& Chen, L. F. (2008). Data mining to improve personel selection and enhance human capital: A casestudy in high-technology industry, Expert Systems with Applications, 34(1), 280-290.

Çalık, E. \& Demir, K. (2020). İnsan Kaynakları Analitiği, Modelleme ve Örnek Uygulamalarla. Nobel Bilimsel Eserler.

Demirci, A. E.\& Kılıç, H. S. (2019). Personnel selection based on integrated multi-criteria decision-making techniques, International Journal of Advances in Engineering and Pure Sciences, 31(2), 163-178.

Fitz-enz, J. (2010). The New HR Analytics: Predicting The Economic Value of Your Company's Human Capital Investments. American Management Association.

Fitz-enz, J., \& Mattox, J. R. (2014). Predictive Analytics for Human Resources. John Wiley\&Sons.

Güngör, Z., Serhadlıŏlu, G., \& Kesen, S. E. (2009). A fuzzy AHP approach to personnel selection problem. Applied Soft Computing, 9(2), 641-646.

Hair, J. F., Black, W. C., Babin, B. J., \& Anderson, R. E. (2014). Multivariate Data Analysis (Seventh). Pearson.

Han, J., Kamber, M., \& Pei, J. (2012). Data Mining Concepts and Techniques (Third Edit). Elsevier.

Handa, D., \& Garima. (2014). Human resource (HR) analytics: Emerging trend in HRM. Internatıonal Journal Of ResearchIn Commerce \& Management, 5(6), 59-62.

Hastie, T., Tibshirani, R., Friedman, J., Hastie, T., Friedman, J., \& Tibshirani, R., (2009). The Elements of Statistical Learning. Springer.

HR Analytics calssification, Veriseti, (2020). https://www.kaggle.com/bhrt97/hr-analytics-classification, Erişim Tarihi: 10.06.2020. 


\section{K. Demir - E. Çalık 12/4 (2020) 3747-3758}

Isson, J. P., \& Harriott, J. S. (2016). People Analytics in the Era of Big Data- Changing the Way You Attract, Acquire, Develop, and Retain Talent. John Wiley\&Sons.

Jantan, H., Hamdan, A. R., \& Othman, Z. A. (2009). Potential data mining classification techniques for academic talent forecasting, Ninth International Conference on Intelligent Systems Design and Applications, 1173-1178, IEEE.

Jantan, H., Hamdan, A. R., \& Othman, Z. A. (2011). Towards applying data mining techniques for talent management, International Conference on Computer Engineering and Applications, IPCSIT, Vol 2.

Jantan, H., Hamdan, A. R., \& Othman, Z. A. (2011). Talent knowledge acquisition using data mining classification techniques, 3rd Conference on Data Mining and Optimization (DMO), 32-37, IEEE.

Jasemi, M., Ahmadi, E. (2018). A new fuzzy ELECTRE based multiple criteria method for personnel selection, Scientia Iranica, 25(2), 943-953.

Korkmaz, O. (2019). Personnel selection method based on TOPSIS multi-criteria decision making method, Uluslararast İktisadi ve İdari İncelemeler Dergisi, (23), 1-16.

Krishankumar, R., Premaladha, J., Ravichandran, K. S., Sekar, K. R., Manikandan, R., \& Gao, X. Z. (2020). A novel extension to VIKOR method under intuitionistic fuzzy context for solving personel selection problem, Soft Computing, 24(2), 1063-1081.

Kuşakcı, A. O., Ayvaz, B., Öztürk, F., \& Feyza, S. O. F. U. (2019). Bulanık MULTIMOORA ile personel seçimi: Havacılık sektöründe bir uygulama, Ömer Halisdemir Üniversitesi Mühendislik Bilimleri Dergisi, 8(1), 96-110.

Malisetty, S., Archana, R. V, \& Kumari, K. V. (2017). Predictive analytics in HR management. Indian Journal of Public Health Research \& Development, 8(3), 115.

Mishra, S. N., Lama, D. R., \& Pal, Y. (2016). Human resource predictive analytics (HRPA) for HR management in organizations. International Journal of ScientificETechnology Research, 5(5), 33-35.

Özkan, Y. (2016). Veri Madenciliği Yöntemleri (3. Basım). Papatya Bilim Yayıncılık.

Pessach, D., Singer, G., Avrahami, D., Ben-Gal, H. C., Shmueli, E., \& Ben-Gal, I. (2020). Employees recruitment: A prescriptive analytics approach via machine learning and mathematical programming." Decision Support Systems, Volume 134, 113290

Ployhart, R. E., Schmitt, N., \& Tippins, N. T. (2017). Solving the supreme problem: 100 years of selection and recruitment at the journal of applied psychology. Journal of Applied Psychology, 102(3), 291.

Salehi, K. (2016). An integrated approach of fuzzy AHP and fuzzy VIKOR for personel selection problem, Global Journal of Management Studies and Researches, 3(3), 89-95.

Shehu, M. A., \& Saeed, F. (2016). An adaptive personel selection model for recruitment using domain-driven data mining, Journal of Theoretical and Applied Information Technology, 91(1), 117.

Shehu, V. \& Besimi, A. (2018). Improving employee recruitment through data mining, World Conference on Information Systems and Technologies, Springer, Cham, 194-202.

Silahtaroğlu, G. (2013). Veri Madenciliği Kavram ve Algoritmaları (3. Basım). Papatya Bilim Yayıncılık.

Vatansever, K., \& Oncel, M. (2014). An implementation of integrated multi-criteria decision making techniques for academic staff recruitment, Journal of Management Marketing and Logistics, 1(2), 111-126.

Vinchur, A. J., \& Bryan, L. L. K. (2012). A history of personnel selection and assessment. The Oxford handbook of personnel assessment and selection, 9-30. 